This item was submitted to Loughborough's Research Repository by the author.

Items in Figshare are protected by copyright, with all rights reserved, unless otherwise indicated.

\title{
Specific two-photon imaging of live cellular and deep-tissue lipid droplets by lipophilic AIEgens at ultra-low concentration
}

\section{PLEASE CITE THE PUBLISHED VERSION}

https://doi.org/10.1021/acs.chemmater.8b01943

\section{PUBLISHER \\ (C) American Chemical Society}

\section{VERSION}

AM (Accepted Manuscript)

\section{PUBLISHER STATEMENT}

This work is made available according to the conditions of the Creative Commons Attribution-NonCommercialNoDerivatives 4.0 International (CC BY-NC-ND 4.0) licence. Full details of this licence are available at: https://creativecommons.org/licenses/by-nc-nd/4.0/

\section{LICENCE}

CC BY-NC-ND 4.0

\section{REPOSITORY RECORD}

Niu, Guangle, Ruoyao Zhang, John P. Kwong, Jacky W.Y. Lam, Congping Chen, Jianguo Wang, Yuncong Chen, et al.. 2018. "Specific Two-photon Imaging of Live Cellular and Deep-tissue Lipid Droplets by Lipophilic Aiegens at Ultra-low Concentration". Loughborough University. https://hdl.handle.net/2134/33947. 


\title{
Specific Two-Photon Imaging of Live Cellular and Deep-Tissue Lipid Droplets by Lipophilic AIEgens at Ultra-Low Concentration
}

\author{
Guangle Niu, ${ }^{\dagger, \neq, \#}$ Ruoyao Zhang, ${ }^{\ddagger, \S, \#}$ John P. C. Kwong, ${ }^{\dagger, \ddagger, \#}$ Jacky W. Y. Lam, ${ }^{\dagger, \ddagger}$ Congping Chen, \\ Jianguo Wang, ${ }^{+, \ddagger}$ Yuncong Chen, ${ }^{+, \ddagger}$ Xing Feng, ${ }^{+, \ddagger}$ Ryan T. K. Kwok, ${ }^{+, \neq}$Herman H.-Y. Sung, ${ }^{,}$Ian \\ D. Williams, ${ }^{\ddagger}$ Mark R. J. Elsegood, ${ }^{\perp}$ Jianan Qu, ${ }^{\prime}$ Chao Ma, ${ }^{\nabla}$ Kam Sing Wong, ${ }^{, X}$ Xiaoqiang Yu, ${ }^{*,}$ \\ and Ben Zhong Tang, ${ }^{*,+, \pm,}$
}

${ }^{\dagger}$ HKUST-Shenzhen Research Institute, No. 9 Yuexing 1st RD, South Area, Hi-tech Park, Nanshan, Shenzhen 518057, China

${ }^{\ddagger}$ Department of Chemistry, Hong Kong Branch of Chinese National Engineering Research Center for Tissue Restoration and Reconstruction, Institute for Advanced Study, Division of Biomedical Engineering and Division of Life Science, The Hong Kong University of Science and Technology, Clear Water Bay, Kowloon, Hong Kong 999077, China

${ }^{\S}$ Center of Bio and Micro/Nano Functional Materials, State Key Laboratory of Crystal Materials, Shandong University, Jinan 250100, China

"Department of Electronic and Computer Engineering, The Hong Kong University of Science and Technology, Clear Water Bay, Kowloon, Hong Kong 999077, China

${ }^{\perp}$ Chemistry Department, Loughborough University, Loughborough LE11 3TU, U.K.

${ }^{D}$ Department of Physics, The Hong Kong University of Science and Technology, Clear Water Bay, Kowloon, Hong Kong 999077, China

${ }^{\top}$ NSFC Center for Luminescence from Molecular Aggregates, SCUT-HKUST Joint Research Institute, State Key Laboratory of Luminescent Materials and Devices, South China University of Technology, Guangzhou 510640, China

Supporting Information Placeholder

\begin{abstract}
Lipid droplets are highly associated with obesity, diabetes, inflammatory disorders and cancer. A reliable two-photon dye for specific lipid droplets imaging in live cells and live tissues at ultra-low concentration has rarely been reported. In this work, four new aggregation-induced emission luminogens (AIEgens) based on the naphthalene core were designed and synthesized for specific two-photon lipid droplets staining. The new molecules, namely NAP AIEgens, exhibit large Stokes shift (>110 nm), high solid-state fluorescence quantum yield (up to 30\%), good two-photon absorption cross section (45-100 GM at $860 \mathrm{~nm}$ ), high biocompatibility and good photostability. They could specifically stain lipid droplets at ultra-low concentration $(50 \mathrm{nM})$ in a short time of $15 \mathrm{~min}$. Such ultra-low concentration is the lowest value for lipid droplets staining in live cells reported so far. In vitro and ex vivo two-photon imaging of lipid droplets in live cells and live mice liver tissues were successfully demonstrated. In addition, selective visualization of lipid droplets in live mice liver tissues could be achieved at a depth of about $70 \mu \mathrm{m}$. These excellent properties render them as promising candidates for investigating lipid droplets-associated physiological and pathological processes in live biological samples.
\end{abstract}

Lipid droplets are ubiquitous lipid-rich spherical organelles in most cells and organisms. Lipid droplets mainly contain triglycerides and cholesterol esters and are enclosed by a phospholipid monolayer with specific proteins. ${ }^{1}$ Lipid droplets as dynamic organelles are involved in many cellular functions, including lipid metabolism, membrane synthesis and transfer, signal transduction, protein degradation and so on. ${ }^{2}$ Recent studies have shown that lipid droplets are also highly associated with obesity, diabetes, inflammatory disorders and cancer. ${ }^{3}$ Imaging techniques, such as transmission electron mi- croscopy, Raman microscopy and immunofluorescence microscopy, have been utilized to visualize lipid droplets, but such methods suffer from complicated procedures and poor cellular permeability and may disturb the functions of cells. ${ }^{4-6}$ Therefore, the development of effective methods for direct and selective lipid droplets visualization and monitoring in biological samples containing live cells and live tissues is of great importance.

Fluorescence imaging has become an indispensable tool for visualizing the localization and the dynamics of cellular compartments and molecular processes due to its 
excellent selectivity, remarkable sensitivity and extraordinary temporal/spatial resolution. ${ }^{7-9}$ Compared with onephoton fluorescence imaging, two-photon fluorescence imaging utilizes two near-infrared (NIR) photons as the excitation source and is beneficial for biomedical imaging because of deeper tissue penetration, higher spatial resolution, lower background fluorescence and lower photodamage and photobleaching. ${ }^{10,11}$

Nile Red and BODIPY 493/503 (Scheme S1 in the Electronic Supporting Information) are commercially used fluorescent dyes for lipid droplets staining, but show some drawbacks. ${ }^{12,13}$ Nile Red shows undesirable background staining and broad emission to limit its application in multicolor imaging. BODIPY 493/503, on the other hand, exhibits very small Stokes shifts to trigger nonradiative energy loss and interference from the scattered light. Great efforts have been made to develop novel lipid Scheme 1. Molecular structures of AIEgens for lipid droplets staining developed by our group

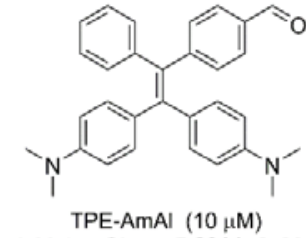

J. Mater. Chem. B 2014, 2, 2013 (One-photon)

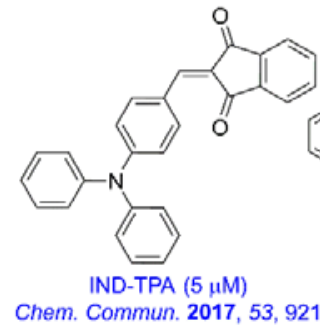

(Two-photon live cell imaging)

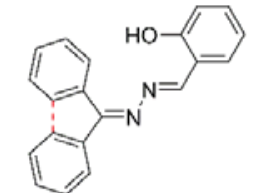

FAS \& DPAS $(7.5 \mu \mathrm{M})$ ACS Appl. Mater. Interfaces 2016, 8, 10193 (One-photon) droplets dyes to solve these problems. ${ }^{12-21}$ Because the normal concentration used for lipid droplets staining falls in the range of 5-10 $\mu \mathrm{M}$ or even higher, these dyes show weak emission due to the aggregation-caused quenching (ACQ) effect. ${ }^{22}$ Few dyes have been synthesized for lipid droplets imaging and function at nano-molar concentrations. However, they show non-specific staining and exhibit blue emission in live cells to result in low signal-tonoise ratio. ${ }^{23-25}$ These ACQ-based dyes also show small Stokes shifts and pretty low photostability. Their use in two-photon deep-tissue imaging is rarely explored. ${ }^{17,25}$ Thus, these limitations prompt us to search for new fluorescent dyes with better properties such as two-photon deep-tissue imaging, low incubation concentration, large Stokes shift, high photostability and high biocompatibility for selective lipid droplets imaging.
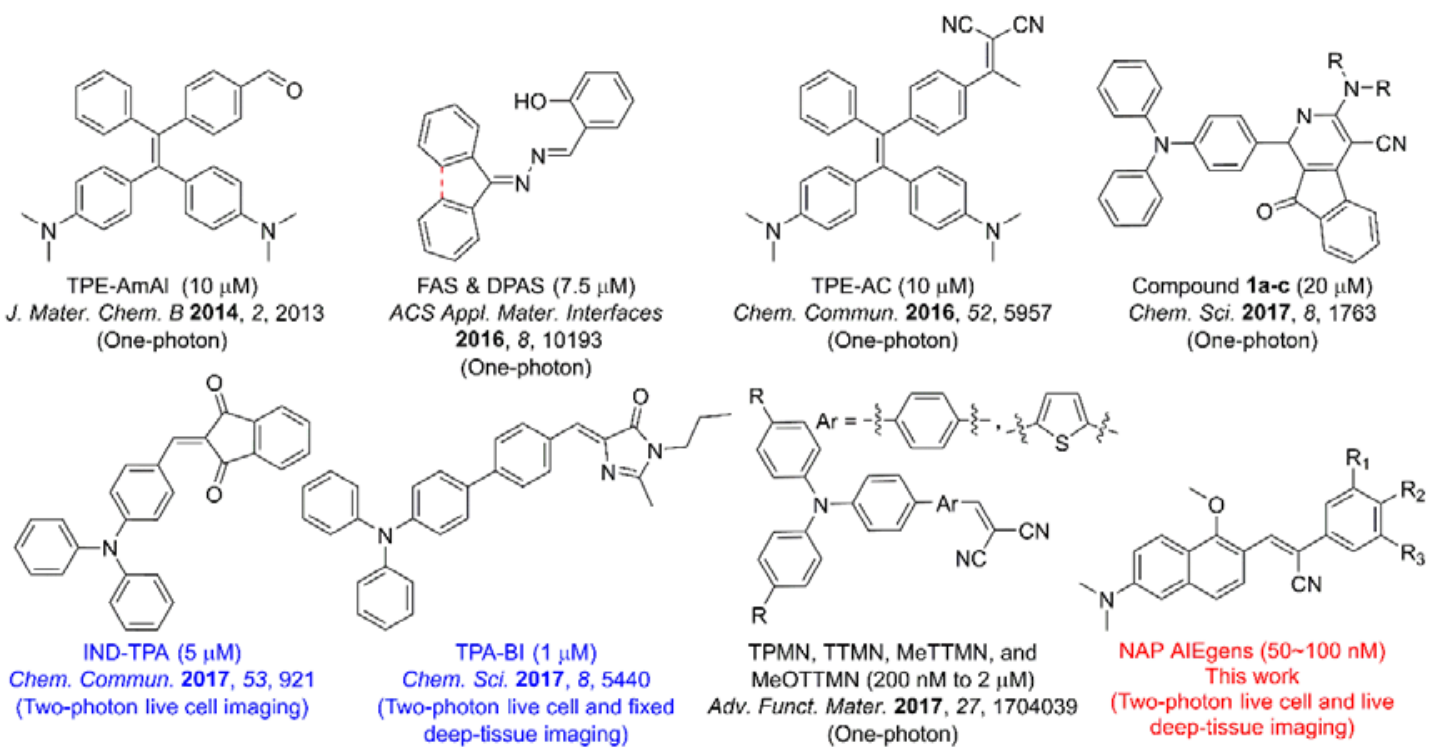

Scheme 2. Molecular structures of NAP AIEgens for specific two-photon lipid droplets staining in the present work

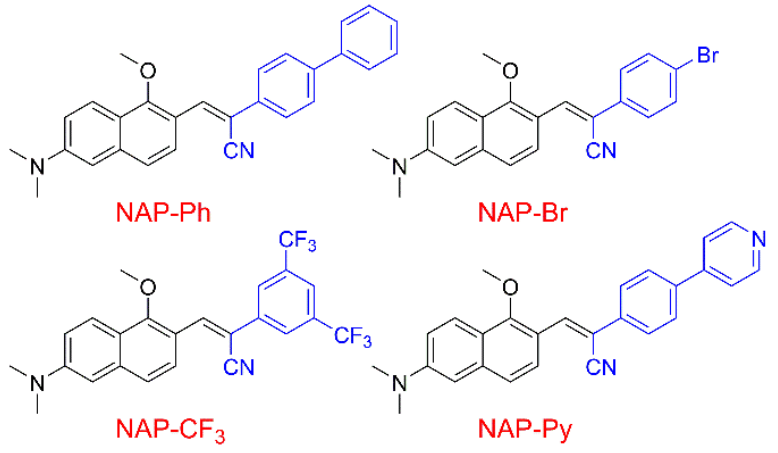

Our group proposed a phenomenon of aggregationinduced emission (AIE), which is exact opposite of the ACQ effect. ${ }^{26}$ Because the AIE phenomenon is of academic value and practical implication, many AIE luminogens (AIEgens) have been synthesized and applied in chemosensing, ${ }^{27}$ bioprobe, ${ }^{28}$ bioimaging, ${ }^{29}$ diagnosis and thera$\mathrm{py}^{30}{ }^{30}$ organic light-emitting diodes ${ }^{31}$ and other applications. ${ }^{32-35}$ Recently, our group has developed several

AIEgens (Scheme 1) with multicolour emissions, high photostability and biocompatibility for selective lipid droplets imaging. ${ }^{36-42}$ Based on electron-donating triphenylamine group, two-photon-active AIEgens named IND-TPA and TPA-BI for selective lipid droplets staining were synthesized by introducing different acceptors (Scheme 1). ${ }^{40},{ }^{41}$ We successfully applied these two AIEgens for two-photon lipid droplets imaging in live cells and further used TPA-BI for two-photon imaging in fixed tissue. Considering that the use of high dye concentration for live sample imaging may affect the normal physiological activity of the cells, it is therefore imperative to develop new two-photon AIEgens that can function at a low incubation concentration. In addition, what is the inherent force to drive the above-mentioned ACQ dyes and AIEgens to lipid droplets in live cells? Moreover, very scant attention has been paid to investigate the relationship between inherent features of dye molecules and their lipid droplets staining properties in live cells. ${ }^{43}$

Due to high components of triglycerides and cholesterol esters, the inherent environment of lipid droplets is lipophilic. Therefore, lipophilic organic dyes with high 
hydrophobicity probably show potential lipid droplets staining ability. Organic dyes with donor-acceptor structures have been studied for a long time. By increasing the electron-withdrawing ability of the acceptor by introducing large heterocyclic ring, the resulting organic dyes generally show redder fluorescence, higher hydrophobicity and larger two-photon absorption cross section but lower cell penetrability. The balance between hydrophobicity and cell penetrability thus should be carefully adjusted. However, there is very limited room to achieve such goal. On the other hand, naphthalene-based donoracceptor molecules have been demonstrated as twophoton probes for fluorescence detection and bioimaging in live cells. ${ }^{44}$ However, naphthalene has rarely been used as core for constructing AIEgens. Herein, by introducing different acceptor units, we synthesized a novel family of two-photon naphthalene-based donor-acceptor AIEgens abbreviated as NAP AIEgens (Scheme 2) for specific twophoton lipid droplets visualization in live cells and live tissues at ultra-low concentration. Their photophysical properties were investigated by one- and two-photon fluorescence spectroscopy, single-crystal X-ray diffraction and density functional theory (DFT) calculations. Their specificity for lipid droplets-staining was studied by confocal (one-photon) and two-photon imaging microscopy as well as calculated $\log \mathrm{P}(\mathrm{C} \log \mathrm{P})$.

\section{RESULTS AND DISCUSSION}

Design and Synthesis. The synthetic routes of NAP AIEgens are depicted in Scheme 3. Compound 1 was synthesized according to the previous work. ${ }^{45}$ Methylation of compound 1 using $\mathrm{CH}_{3} \mathrm{I}$ generated compound 2. Compound 2 then reacted with phenylacetonitriles with different substituents on the phenyl ring (compounds 3, 4 and 5 ) in the presence of $t$-BuOK in refluxed anhydrous ethanol to give NAP-Ph, NAP-Br and NAP- $\mathrm{CF}_{3}$. NAP-Py was obtained by Suzuki coupling reaction of NAP-Br and compound 6. Afterwards, methylation and then anion exchange of NAP-Py gave NAP-Py'. The structures of all the intermediates and products were fully characterized by ${ }^{1} \mathrm{H}$ NMR, ${ }^{13} \mathrm{C}$ NMR, ${ }^{19} \mathrm{~F}$ NMR and HRMS spectroscopy with satisfactory analysis results. Detailed synthetic procedure and characterization data were provided in Figures $\mathrm{S}_{1-20}$ in the Electronic Supporting Information.

\section{Scheme 3. Synthetic routes to NAP AIEgens}

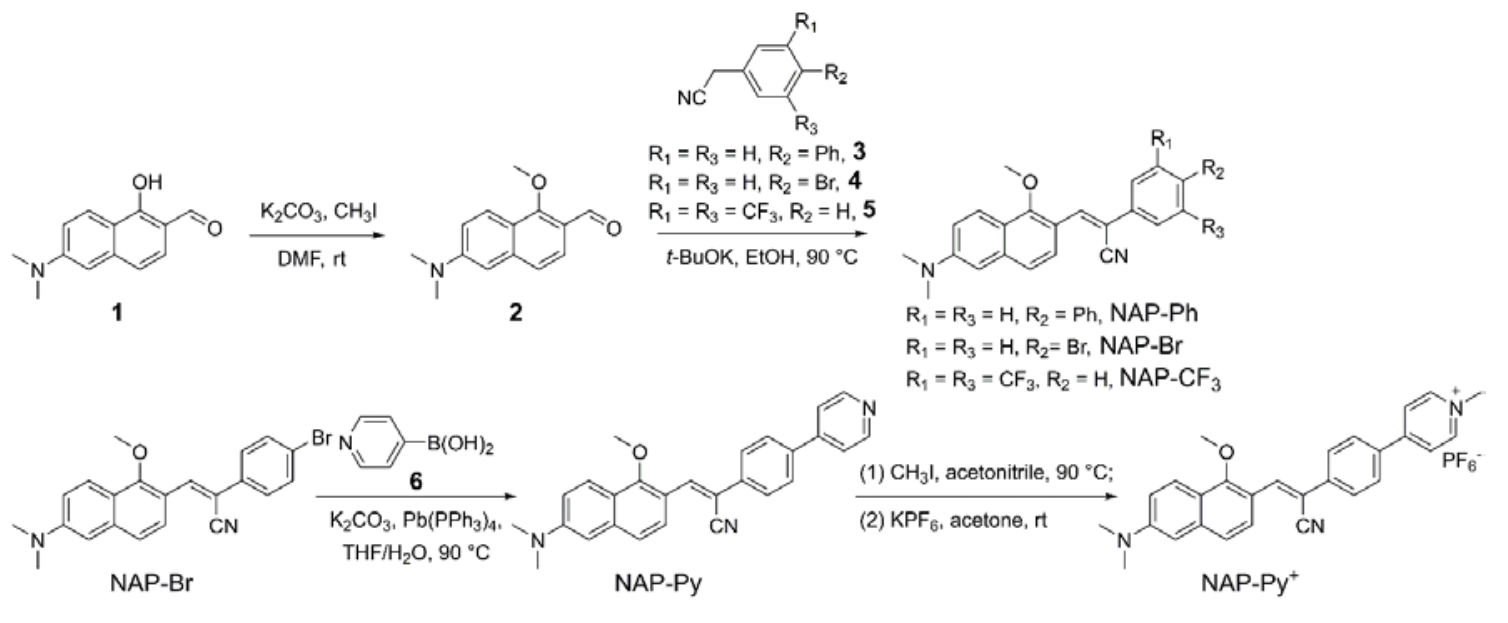

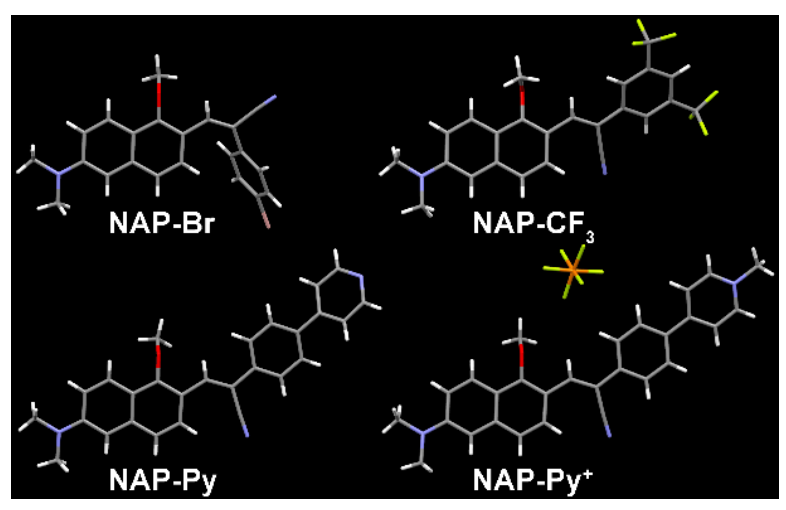

Figure 1. Single crystal structures of NAP AIEgens with atoms labeled in color. $\mathrm{C}$, gray; $\mathrm{H}$, white; $\mathrm{N}$, blue; $\mathrm{O}$, red; F, yellow; $\mathrm{Br}$, pink; $\mathrm{P}$, orange.

X-ray Crystal Structures. The structures of NAP AIEgens were confirmed by single-crystal X-ray diffraction (Figure 1). Single crystals of NAP AIEgens suitable for analysis were obtained by slow evaporation of their solvent mixture of $\mathrm{CH}_{2} \mathrm{Cl}_{2}$ and $\mathrm{MeOH}(3: 1, \mathrm{v} / \mathrm{v})$ at ambient temperature. The ORTEP drawings of the molecules were given in the Figures S21-24 and the details of the experimental conditions, unit cell data, and refinement data were summarized in Tables $\mathrm{S}_{1}-\mathrm{S}_{4}$. It is noteworthy that the NAP-Br crystals possessed a $E$ conformation (Figure 1), which was in good agreement with the ${ }^{1} \mathrm{H}$ NMR data shown in Figures $\mathrm{S}_{25}-\mathrm{S}_{2} 6$. All the molecules showed $\pi-\pi$ interaction between molecules and stacking between the $\pi$-units was observed in crystals of NAP-Br, NAP-Py, and NAP-Py ${ }^{+}$(Figures S27A-D). Multiple intramolecular interactions such as $\mathrm{C}-\mathrm{H} \cdots \mathrm{O}, \mathrm{C}-\mathrm{H} \cdots \mathrm{N}, \mathrm{C}-\mathrm{H} \cdots \mathrm{F}$ and $\mathrm{C}-\mathrm{F} \cdots \mathrm{F}$ interactions existed in the crystal lattices (Figure S28), which prevented the loss of excited-state energy through nonradiative decay channels by intramolecular motion to enable the molecules to emit in the solid state. The intermolecular $\mathrm{C}-\mathrm{H} \cdots \mathrm{N}$ interaction is probably the main driving force for the formation of NAP-Br crystals with $E$ 
isomeric conformation. On the other hand, the molecules of NAP-Br, NAP-Py, and NAP-Py ${ }^{+}$in the crystal lattice were arranged in a head-to-tail arrangement (Figures S27A, C and D), suggestive of the formation of $J$ aggregates. Previous studies showed that the angle $\left(0^{\circ}<\right.$ $\left.\theta_{1}<54.71^{\circ}\right)$ between the molecular plane and the aggregation direction determined the occurrence of $J$ aggregation. $^{46,47}$ The angle $\left(\theta_{1}\right)$ determined in NAP-Br, NAP-Py, and NAP-Py ${ }^{+}$was $37.15^{\circ}, 19.95^{\circ}$ and $31.54^{\circ}$, respectively, demonstrating that these AIEgens did form $J$ aggregation. Unlike NAP-Py and NAP-Py ${ }^{+}$, no $J$-aggregates was formed in NAP- $\mathrm{CF}_{3}$ probably due to its more twisted structure (Figure $\mathrm{S}_{27} \mathrm{E}$ ). The dihedral angles $\left(\theta_{2}\right)$ between the naphtha-lene (green color) and benzene planes (purple color) in NAP-CF $-\mathrm{NAP}-\mathrm{Py}$, and NAP-Py ${ }^{+}$are $36.68^{\circ}$, $1.20^{\circ}$ and $5.45^{\circ}$, respectively (Figure $\mathrm{S}_{27} \mathrm{E}$ ). The large angle value in $\mathrm{NAP}-\mathrm{CF}_{3}$ verified its highly twisted structure.
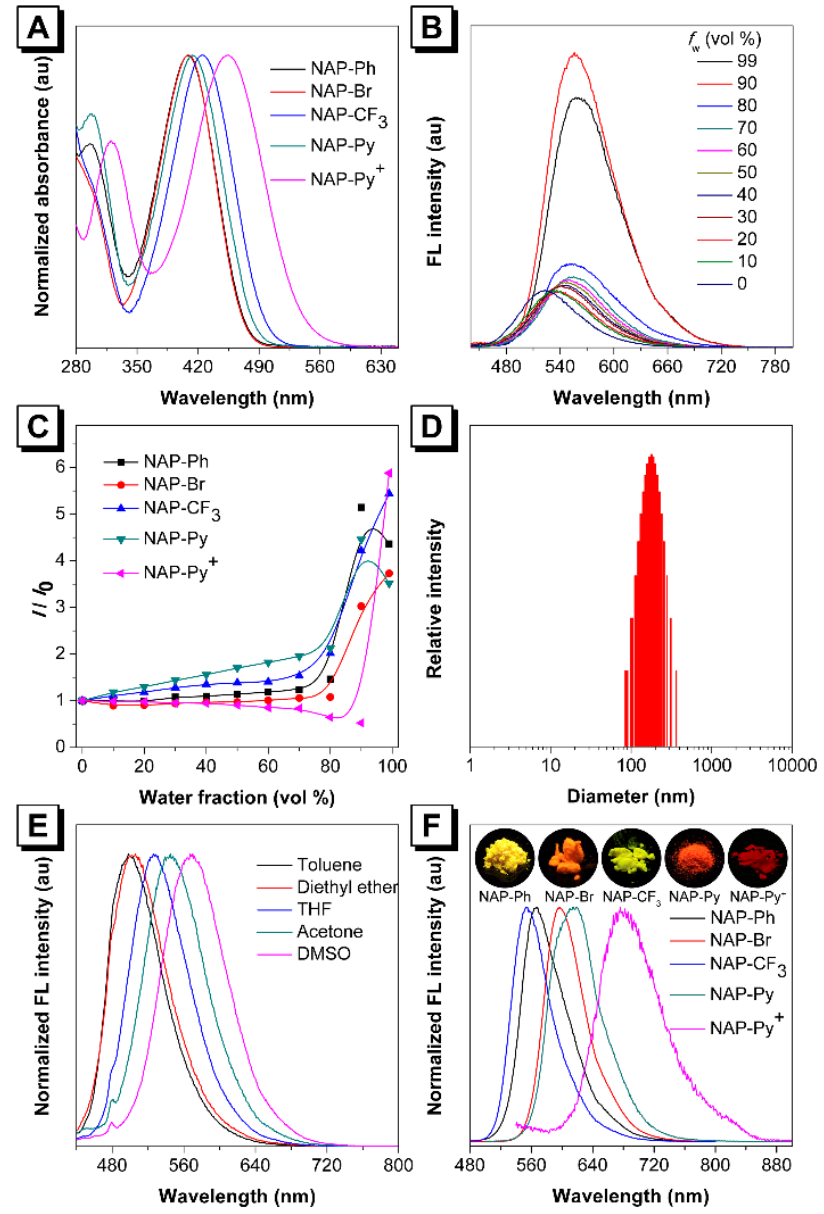

Figure 2. (A) Normalized absorption spectra of NAP AIEgens $(10 \mu \mathrm{M})$ in THF or $\mathrm{CH}_{3} \mathrm{CN}$. (B) FL spectra of NAP-Ph (1o $\mu \mathrm{M})$ in THF and THF/water mixtures with different water fractions $\left(f_{\mathrm{w}}\right)$. (C) Plots of FL emission intensity ver-sus the composition of the THF/water mixtures or $\mathrm{CH}_{3} \mathrm{CN} /$ water mixtures of NAP AIEgens $(10 \mu \mathrm{M})$. (D) The dynamic light scattering data of NAP-Ph (1o $\mu \mathrm{M})$ in water containing $1 \%$ THF. Hydrated diameter: $178 \mathrm{~nm}$. (E) Nor-malized fluorescence spectra of NAP-Ph in different polar solvents. (F) Normalized FL spectra of NAP
AIEgens in the solid state. Inset: Fluorescent photos of solids of NAP AIEgens taken under $365 \mathrm{~nm}$ UV irradiation from a hand-hold UV lamp.

Photophysical property. The absorption and fluorescence (FL) spectra of NAP AIEgens are shown in Figures 2 and $\mathrm{S}_{29}-\mathrm{S}_{32}$ and the data are summarized in Table 1. NAP-Ph showed an absorption maximum $\left(\lambda_{\text {abs }}\right)$ at $409 \mathrm{~nm}$ and an emission maximum $\left(\lambda_{\mathrm{em}}\right)$ at $523 \mathrm{~nm}$ in dilute THF solution (Figures $2 \mathrm{~A}$ and $2 \mathrm{~B}$ ). Addition of water to the THF solution slight red shifted its emission, while the FL intensity decreased initially and then increased afterwards when the water fraction $\left(f_{\mathrm{w}}\right)$ exceeded $20 \%$. At $f_{\mathrm{w}}=90 \%$, NAP-Ph emitted intensity at $557 \mathrm{~nm}$ due to the formation of aggregates (Figure $2 \mathrm{~B}$ ), indicative of an aggregationenhanced emission (AEE) property. The FL intensity dropped when the $f_{\mathrm{w}}$ was further increased to $99 \%$. Such phenomenon is often observed in AIEgens and is associated with the change of the morphology and size of the aggregates formed in aqueous mixtures with high water fractions. ${ }^{34}$ Other molecules are also AEE-active as proved by the FL analysis (Figure S29). It should be noted that the FL of NAP AIEgens in aqueous suspensions is only several-fold stronger than that in THF (NAP-Ph, NAP-Br, $\mathrm{NAP}-\mathrm{CF}_{3}$ and NAP-Py) or $\mathrm{CH}_{3} \mathrm{CN}\left(\mathrm{NAP}-\mathrm{Py}^{+}\right.$, due to its low solubility in THF) (Figure $2 \mathrm{C}$ ), probably the formed aggregates are of loosely packing. In addition, the dynamic light scattering data showed that these NAP AIEgens exhibited different hydrated diameters ranging from $119 \mathrm{~nm}$ to $274 \mathrm{~nm}$ in water solution with $1 \%$ THF (NAP-Ph, NAP$\mathrm{Br}, \mathrm{NAP}-\mathrm{CF}_{3}$, and NAP-Py) or $1 \% \mathrm{CH}_{3} \mathrm{CN}\left(\mathrm{NAP}-\mathrm{Py}{ }^{+}\right.$) (Figure $2 \mathrm{D}$ and $\mathrm{S}_{30}$ ), successfully demonstrating the existence of aggregates. NAP AIEgens possess donor-acceptor structures and their electron-withdrawing ability is in the order of NAP-Py ${ }^{+}>\mathrm{NAP}-\mathrm{CF}_{3}>\mathrm{NAP}-\mathrm{Py}>\mathrm{NAP}-\mathrm{Br}>\mathrm{NAP}-\mathrm{Ph}$. The stronger electron-withdrawing ability leads to better electronic communication to result in redder absorption in NAP-Py ${ }^{+}$and shorter $\lambda_{\text {abs }}$ in NAP-Ph. The FL of NAP AIEgens were further studied in solvents with different polarities (Figure $2 \mathrm{E}$ and $\mathrm{S}_{31}$ ). The $\lambda_{\mathrm{em}}$ of NAP-Ph, NAP$\mathrm{Br}$, NAP- $\mathrm{CF}_{3}$, and NAP-Py gradually red-shifted when the solvent was changed from toluene to diethyl ether, THF, acetone and then DMSO. This indicates that they exhibit positive solvatochromism due to the intramolecular charge transfer effect. However, NAP-Py ${ }^{+}$showed negative solvatochromism. Except $\mathrm{NAP}-\mathrm{CF}_{3}$, all the molecules emitted redder in the solid state $(555-676 \mathrm{~nm})$ than in the solution (Figure $2 \mathrm{~F}$ and Table 1 ), due to the $J$-aggregate formation. $\mathrm{NAP}-\mathrm{CF}_{3}$ may take a more twisted structure in the solid state than in solution to result in its blue-shifted emission in the solid state. It is worth to mention that NAP AIEgens exhibit large Stokes shifts (Table 1). Such property helps reduce self-absorption to afford high resolution and facilitate multichannel bioimaging. ${ }^{45}$ The FL quantum yields of NAP AIEgens were measured by using an integrating sphere. All the molecules show low quantum yields in organic solvents because the active intramolecular motion consumed the energy of the excited state through non-radiative processes. However, such motion was restricted in the solid-state due to multiple intramo- 
lecular interactions to result in high FL quantum yields. The solid-state FL quantum yield of NAP-Py ${ }^{+}$was low due to its narrow energy gap to enhance nonradiative transitions (Figure $\left.\mathrm{S}_{33}\right) .^{48}$ The FL lifetime in the solution and solid state was also checked. The longer value in the solid state than in solutions verified that the restriction of intramolecular motion could prohibit energy dissipation via non-radiative channels to enhance the FL of NAP AIEgens $\begin{array}{lllll}\text { (Table } & 1 & \text { and } & \text { Figure } & \text { S32). }\end{array}$

Table 1. Photophysical Properties of NAP AIEgens ${ }^{a}$

\begin{tabular}{|c|c|c|c|c|c|c|c|c|}
\hline \multirow[b]{2}{*}{ AIEgen } & \multicolumn{5}{|c|}{ Solution } & \multicolumn{3}{|c|}{ Solid } \\
\hline & $\lambda_{\mathrm{abs}}(\mathrm{nm})$ & $\lambda_{\mathrm{em}}(\mathrm{nm})$ & $\begin{array}{l}\text { Stokes shift } \\
\quad(\mathrm{nm})\end{array}$ & $\Phi_{\mathrm{F}, \mathrm{S}}(\%)$ & $\tau(\mathrm{ns})$ & $\lambda_{\mathrm{em}}(\mathrm{nm})$ & $\Phi_{\mathrm{F}, \mathrm{P}}(\%)$ & $\tau(\mathrm{ns})$ \\
\hline NAP-Ph & 409 & 523 & 114 & 1.8 & $<0.34$ & 566 & 26.8 & 1.42 \\
\hline NAP-Br & 409 & $5^{25}$ & 116 & 1.4 & $<0.60$ & 597 & 12.6 & $4 \cdot 43$ \\
\hline $\mathrm{NAP}-\mathrm{CF}_{3}$ & 425 & 560 & 135 & 1.6 & $<0.67$ & 555 & 29.2 & 6.29 \\
\hline NAP-Py & 413 & 541 & 128 & 1.5 & $<0.67$ & 619 & 21.7 & 1.39 \\
\hline NAP-Py ${ }^{+}$ & 455 & 540 & 85 & 0.8 & $<0.58$ & 676 & 4.8 & 1.32 \\
\hline
\end{tabular}

${ }^{a}$ Abbreviation: $\lambda_{\mathrm{abs}}=$ absorption maximum; $\lambda_{\mathrm{em}}=$ emission maximum; $\Phi_{\mathrm{F}, \mathrm{S}}$ and $\Phi_{\mathrm{F}, \mathrm{P}}=$ fluorescence quantum yield in solution and solid powder, respectively; $\tau$ (ns) = fluorescence lifetime.

Theoretical calculation. DFT calculations were performed at the $\mathrm{B}_{3} \mathrm{LYP} / 6-31 \mathrm{G}$ level of theory by using the Gaussian o9 program package to further investigate the optical properties of NAP AIEgens. ${ }^{49}$ Figure S33 shows the calculated HOMOs and LUMOs of NAP AIEgens. The orbitals of HOMOs of NAP AIEgens were mainly delocalized on the whole molecules especially in the substituted naphthalene ring. The LUMOs, on the other hand, were mainly contributed by the orbitals of the cyanostilbene unit. Obvious orbital separation of HOMOs and LUMOs was observed in NAP-Py ${ }^{+}$due to its strong intramolecular charge transfer effect. The energy band gap decreased in the order of NAP-Py ${ }^{+}>\mathrm{NAP}-\mathrm{CF}_{3}>\mathrm{NAP}-\mathrm{Py}>\mathrm{NAP}-\mathrm{Br}>$ $\mathrm{NAP}-\mathrm{Ph}$ due to the progressive increase in the electronaccepting ability. This lead to red-shift in absorption, which is in good accordance with the measured photophysical data (Table 1 ).

Two-photon excited fluorescence. Previous studies showed that naphthalene-based donor-acceptor molecules exhibited two-photon absorption. ${ }^{44}$ NAP AIEgens possess conjugated donor-acceptor structures and they are thus anticipated to show two-photon absorption property. To demonstrate this, the two-photon excited fluorescence of aggregate suspensions of NAP AIEgens in $\mathrm{H}_{2} \mathrm{O}$ containing $10 \%$ THF (NAP-Ph, NAP-Br, NAP-CF 3 and NAP-Py) or $1 \%$ $\mathrm{CH}_{3} \mathrm{CN}$ (NAP-Py ${ }^{+}$) was investigated using a femtosecond pulsed laser as excitation source (800-90o $\mathrm{nm}$ ). As shown

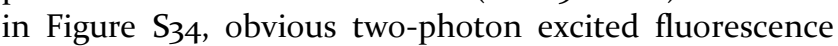
signals were observed in the molecules and their FL spectra resembled to those excited by one-photon, revealing the same excited state for the radiative decay process. Using fluorescein as standard, ${ }^{50}$ the two-photon absorption cross sections $(\delta)$ of the molecules at different wavelengths were measured. Although NAP-Ph, NAP-Br, NAP$\mathrm{CF}_{3}$ and NAP-Py exhibited only moderate $\delta$ values of about $45^{-100} \mathrm{GM}$ at $860 \mathrm{~nm}$, they were still larger than that of fluorescein. ${ }^{50} \mathrm{NAP}-\mathrm{Py}^{+}$showed the highest $\delta$ value due to its large conjugation and strong intramolecular charge transfer effect. ${ }^{10}$ To further study their two-photon excited fluorescence, their solids were directly excited at $800 \mathrm{~nm}$. As shown in Figure $\mathrm{S}_{35}$, even at a low excitation of $\sim 0.35 \mathrm{~mW}$, we could still obtain strong two-photon excited fluorescence signals. Actual two photon response of NAP AIEgens as a function of input intensity was further evaluated. The logarithm of integrated two-photon excited fluorescence $(\log A)$ versus the logarithm of laser intensity ( $\log$ I) showed a good linearity with the slope of 1.673-1.890 (Figure S36), basically confirming the observed emissions indeed arise from two-photon excited fluorescence. These data reveal that the NAP AIEgens are promising contrast agents for two-photon fluorescence imaging.

In vitro one-photon fluorescence imaging. We first performed one-photon cell imaging experiments by confocal laser scanning microscopy to evaluate the biological applications of NAP AIEgens. After incubation in HeLa cells for $15 \mathrm{~min}$, bright fluorescence of NAP AIEgens was observed in the cytoplasm (Figure $\mathrm{S}_{37}$ and $\mathrm{S}_{3} 8$ ), indicating their excellent membrane permeability. The in situ fluorescence spectra of NAP AIEgens in HeLa cells were acquired by using the Lambda mode (Figure S39) and revealed blue-shift emission in live cells probably due to their intramolecular charge transfer effect. ${ }^{41}$

To confirm the intracellular location of NAP AIEgens in live cells, co-staining experiments with Nile Red, a commercial lipid droplets dye, were performed. The molecules of NAP-Ph, NAP-Br, NAP- $\mathrm{CF}_{3}$, and NAP-Py were distributed in HeLa cells in a way similar to that of Nile Red (Figure 3), and the corresponding Pearson's coefficient was $0.90,0.83,0.85$ and 0.88 , respectively. Clearly, they are novel lipid droplets-specific dyes. In contrast, NAP-Py ${ }^{+}$showed a high overlap (Pearson's coefficient of 
o.89) with MitoTracker Deep Red FM, a commercial mitochondria dye (Figure $\mathrm{S}_{40}$ ). It is reasonable because positively-charged dyes like NAP-Py ${ }^{+}$prefer to stain mitochondria due to their high negative membrane potential. ${ }^{51}$ Why do other NAP AIEgens without positive charge locate in lipid droplets?

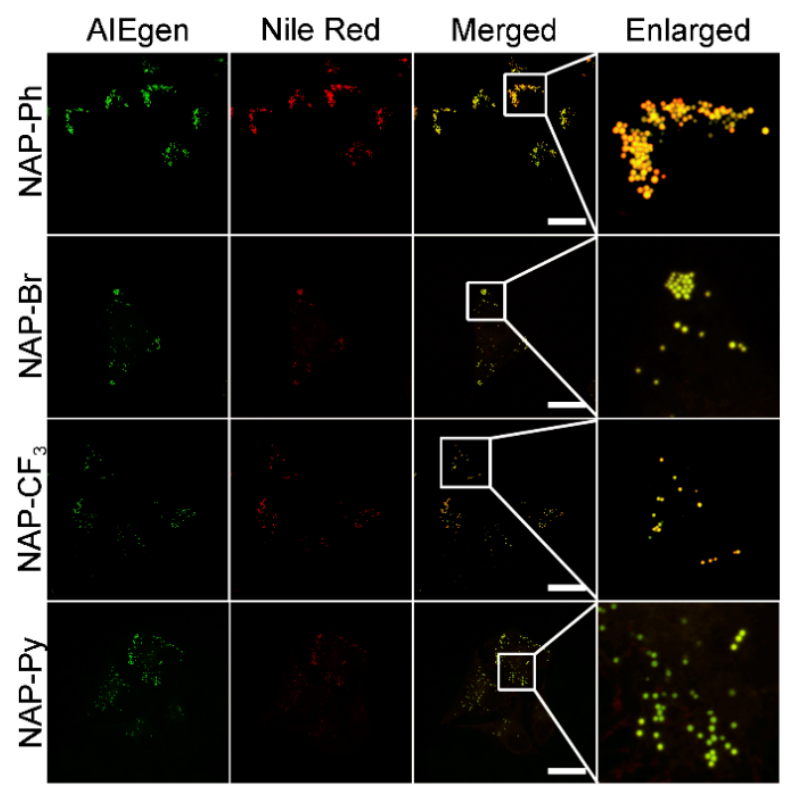

Figure 3. Confocal laser scanning microscopy images of HeLa cells incubated with NAP-Ph, NAP-Br, NAP-CF 3 , NAPPy and Nile Red. Concentration: $100 \mathrm{nM}$. Scale bar: $20 \mu \mathrm{m}$.

To seek a reasonable explanation for the high specificity of NAP AIEgens to lipid droplets, we performed some basic calculations. Considering the inherent lipophilic environment of lipid droplets due to the high component of triglycerides and cholesterol esters, we anticipated that lipophilic organic dyes with high hydrophobicity or high $\log \mathrm{P}$ (n-octanol/water partition coefficient) value will specifically locate in lipid droplets, which was consistent with the theory of similarity and intermiscibility. Here we define $C \log \mathrm{P}$ as calculated $\log \mathrm{P}^{52}$ and its values was estimated using ChemBioDraw 14.0. The $\mathrm{ClogP}$ values of the lipid droplets dyes are summarized in Table $\mathrm{S}_{5}$ and Figure 4 and fall in the range of 3.1-16.643 (Table $\mathrm{S}_{5}$ ). Horobin et al. previously reported that organic dyes for lipid droplets staining usually exhibited $\log \mathrm{P}$ value larger than 5 predicted by using QSAR (quantitative structure activity relations) models. ${ }^{43}$ It is particularly gratifying to note that NAP-Ph, NAP-Br, NAP-CF ${ }_{3}$, and NAP-Py exhibit ClogP values of 5.184-6.681 (Figure 4), which were higher than those of Nile Red (4.618) and BODIPY 493/503 (5.028). The high $C \log P$ values probably could explain why these AIEgens showed better lipid droplets staining performance than Nile Red. The ClogP value of NAP-Py ${ }^{+}$was deduced to be 0.340 , which was too low to meet the requirement for lipid droplets staining. ${ }^{43}$ These semitheoretical data further indicated that these lipophilic AIEgens could specifically locate in lipid droplets.

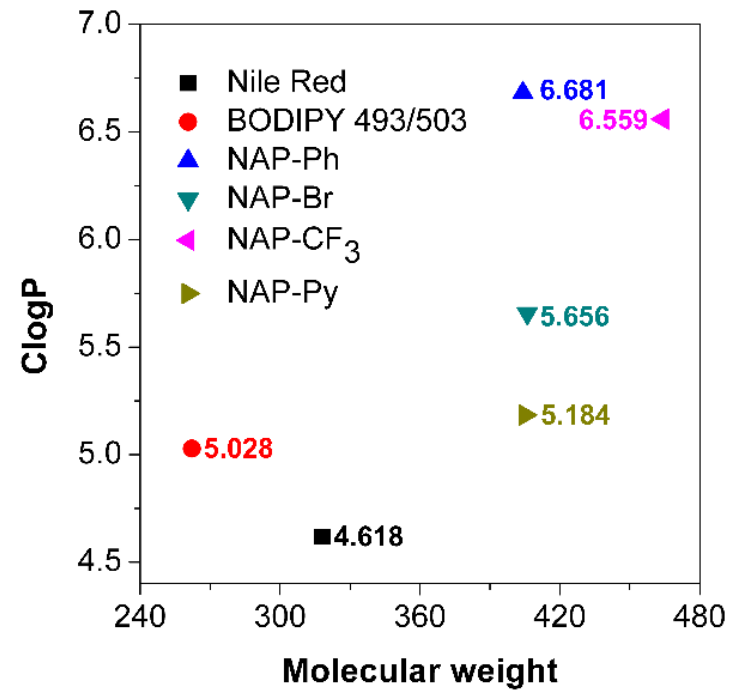

Figure 4. $C \log P$ values of Nile Red, BODIPY 493/503, NAP$\mathrm{Ph}, \mathrm{NAP}-\mathrm{Br}, \mathrm{NAP}-\mathrm{CF}_{3}$, and NAP-Py.

We further performed one-photon imaging experiments in HeLa cells stained with $50 \mathrm{nM}$ of NAP-Ph, NAP$\mathrm{Br}, \mathrm{NAP}-\mathrm{CF}_{3}$, and NAP-Py. The performance of Nile Red was also tested for comparison. To our astonishment, strong fluorescence of NAP AIEgens in lipid droplets with low background fluorescence was also obtained at such low concentration (Figure 5) and low confocal laser intensity ( $405 \mathrm{~nm}$, intensity $=12 \%)$. As far as we know, this is the lowest concentration for lipid droplets imaging. Although Nile Red could also be applied for lipid droplets imaging at such low concentration, it showed nonspecific staining in cytoplasm. This results in low signalto-noise ratio and is in accord with the previous studies. ${ }^{12,}$ ${ }^{13}$ Evidently, the NAP AIEgens show more outstanding lipid droplets staining capacity than Nile Red. Two reasons may account for lipid droplets-specific staining at such ultra-low concentrations: one is the inherent lipophilic properties of the NAP AIEgens, which are demonstrated by their high ClogP values (Figure 4). The other is their enhanced fluorescence in lipid droplets than in solution. To demonstrate the latter reason, we investigated the fluorescence changes of NAP-Ph, NAP-Br, NAP- $-\mathrm{CF}_{3}$, and NAP-Py in the presence of 1,2-dimyristoyl-sn-glycero3-phosphocholine (DMPC) and trioleate glycerol (TAG).

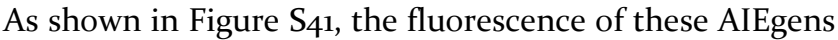
blue-shifted in the presence of DMPC and TAG and their intensity was stronger than that in $\mathrm{PBS}(\mathrm{pH}=7.2)$ by 1.7 3.6 folds. This results in their enhanced fluorescence in live cells and low incubation concentration for specific lipid droplets staining. This is also the reason why the in situ fluorescence of these AIEgens in live cells was observed at shorter-wavelength region (Figures $\mathrm{S}_{37}$ and S39).

Generally, AIE-based dyes show none or low emission in soluble state, but they emit strong fluorescence in the restricted environment. ${ }^{34}$ Previous study reveals that the inner parts of organelles in live cells have different viscosities. ${ }^{53}$ Considering their ultra-low concentrations and intramolecular charge transfer property (Figure $2 \mathrm{E}$ and 
S31), NAP AIEgens showed blue-shifted and enhanced emissions in restricted viscous and nonpolar lipid droplets, while the other parts with high polarity in live cells showed quite low fluorescence with high signal-to-noise ratio. The blue-shifted emissions were confirmed by in situ fluorescence spectra (Figure S39). And the enhanced emissions were demonstrated by in vitro fluorescence spectra (Figure $\mathrm{S}_{41}$ ) in the presence of 1,2-dimyristoyl-snglycero-3-phosphocholine and trioleate glycerol.

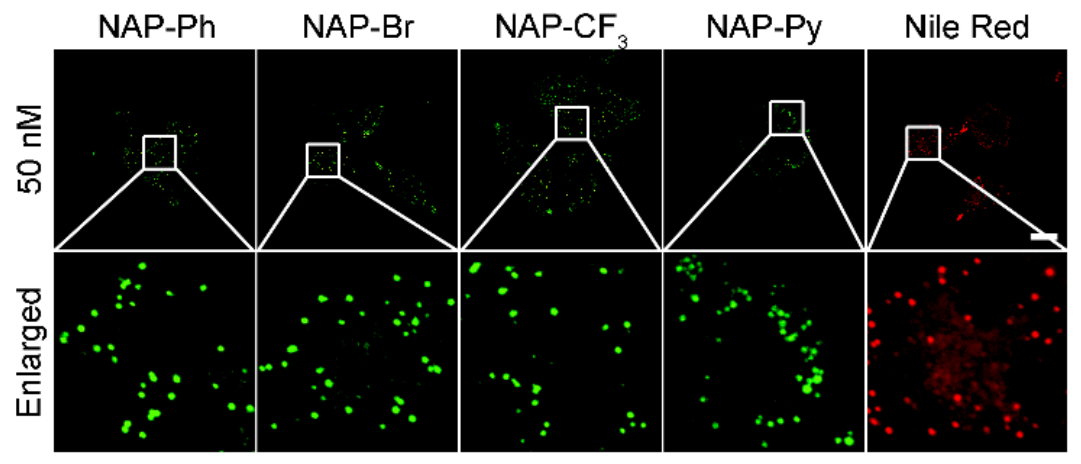

Figure 5. Confocal laser scanning microscopy images of HeLa cells stained with NAP-Ph, NAP-Br, NAP-CF, NAP-Py, and Nile Red. Scale bar: $20 \mu \mathrm{m}$.

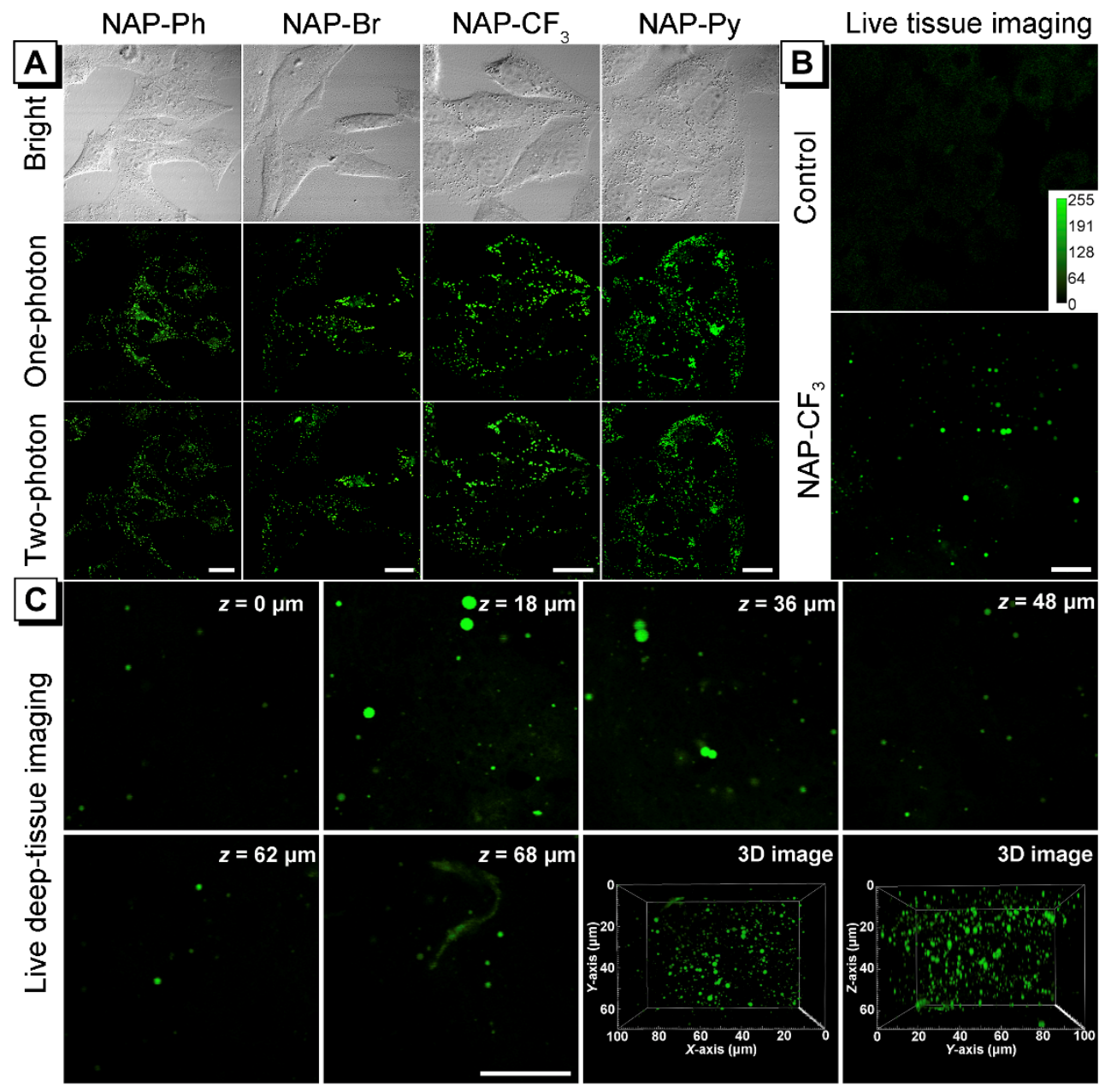

Figure 6. In vitro and ex vivo two-photon imaging of lipid droplets in live cells and live mice liver tissues. (A) In vitro one-photon $\left(\lambda_{\mathrm{ex}}=405 \mathrm{~nm}\right)$ and two-photon $\left(\lambda_{\mathrm{ex}}=860 \mathrm{~nm}\right)$ fluorescent microscopic images of HeLa cells stained with NAP-Ph, NAP-Br, NAP$\mathrm{CF}_{3}$, and NAP-Py in HeLa cells. Concentration: $100 \mathrm{nM}$. Scale bar: $20 \mu \mathrm{m}$. (B) Ex vivo two-photon $\left(\lambda_{\mathrm{ex}}=860 \mathrm{~nm}\right)$ images of live mice liver tissue incubated with or without NAP-CF $(1 \mu \mathrm{M})$. Scale bar: $20 \mu \mathrm{m}$. (C) Ex vivo two-photon $\left(\lambda_{\mathrm{ex}}=860 \mathrm{~nm}\right)$ images of the live mice liver tissue stained with $\mathrm{NAP}_{-} \mathrm{CF}_{3}(1 \mu \mathrm{M})$ at different penetration depths and reconstructed $3 \mathrm{D}$ two-photon images along different axes. Scale bar: $20 \mu \mathrm{m}$. 
In vitro and ex vivo two-photon fluorescence imaging. We have demonstrated that NAP-Ph, NAP-Br, NAP$\mathrm{CF}_{3}$, and NAP-Py displayed good two-photon excited fluorescence with moderate two-photon absorption cross sections (45-100 GM at $860 \mathrm{~nm}$ ). The successful application of these AIEgens for specific lipid droplets staining in live cells with one-photon microscopy encourages us to evaluate their utility in the two-photon mode. We performed two-photon fluorescence imaging of these NAP AIEgens in HeLa cells using an 86o-nm femtosecond pulsed laser. As shown in Figure 6A, bright green fluorescence of lipid droplets was observed in live cells at an excitation wavelength of $860 \mathrm{~nm}$. Such situation was almost identical to that observed under one-photon excitation of $405 \mathrm{~nm}$. Compared with other two-photon fluorophores for in vitro live cell lipid droplets staining, ${ }^{13,21,40,41}$ our NAP AIEgens display better performance in terms of ultra-low concentration and low background fluorescence. These data showed that the present AIEgens show great potential in two-photon fluorescence imaging.

The two-photon fluorescence imaging outperforms imaging in one-photon mode for its high penetration in tissues and low background fluorescence because of nearinfrared light excitation and low excitation power. ${ }^{10,11,54}$ To further demonstrate these merits, ex vivo two-photon imaging of live mice liver tissue incubated with $\mathrm{NAP}-\mathrm{CF}_{3}$ was carried out. After incubation with NAP-CF $(1 \mu \mathrm{M})$ for $1 \mathrm{~h}$, to our surprise, spherical spots with bright twophoton fluorescence of NAP- $\mathrm{CF}_{3}$ were observed (Figure $6 \mathrm{~B})$. The live mice liver tissue incubated with no NAP- $-\mathrm{CF}_{3}$, however, only exhibited low background fluorescence. These data reveal that $\mathrm{NAP}-\mathrm{CF}_{3}$ also displays excellent lipid droplets staining property in live mice liver tissue with quite low background fluorescence. To investigate whether NAP- $\mathrm{CF}_{3}$ show lipid droplets-specific staining in deep live mice liver tissue, we capture the two-photon fluorescent images along the $Z$-axis. As shown in Figure 6C and Movie S1, the fluorescence signal of the spherical spot could be clearly detected along the $Z$-axis at depth of even up to $70 \mu \mathrm{m}$. In addition, $3 \mathrm{D}$ two-photon fluorescent images with high resolution along different visual directions were successfully reconstructed (Figures 6C). Clearly, this demonstrates the high penetration and high signal-to-noise ratio of two-photon imaging of NAP- $\mathrm{CF}_{3}$. Compared with TPA-BI for two-photon lipid droplets imaging in fixed tissue, NAP- $\mathrm{CF}_{3}$ could selectively stain lipid droplets in live tissue at lower incubation concentration (1 $\mu \mathrm{M}$ for $\mathrm{NAP}-\mathrm{CF}_{3}$ and $10 \mu \mathrm{M}$ for TPA-BI), deeper tissue penetration (near $70 \mu \mathrm{m}$ for NAP- $\mathrm{CF}_{3}$ and $45 \mu \mathrm{m}$ for TPA$\mathrm{BI})$ and lower background fluorescence. ${ }^{41}$ One recent work using a luminescent metal complex LD-TPZn shows deeper penetration $(115 \mu \mathrm{m})$ in fixed tissues, however, the procedure for preparing the fixed tissues is complicated and the incubation time of $6 \mathrm{~h}$ at the concentration of 2 $\mu \mathrm{M}$ is quite long. ${ }^{21}$ Fatty liver diseases are characterized by increased level of lipid storage in lipid droplets, and they could progressively lead to chronic liver injury, fibrosis and even hepatocellular cancer. ${ }^{55}$ Oil Red $\mathrm{O}$ staining could be used to diagnose such diseases..$^{56}$ However, Oil
Red $\mathrm{O}$ could only stain lipid droplets in fixed tissues which need complicated procedures and fixed tissue slice preparation is time-consuming. In addition, its sensitivity and penetration is low and shallow in comparison of fluorescence method. Considering its live deep-tissue penetration $(7 \mathrm{o} \mu \mathrm{m})$ and high sensitivity and selectivity, we anticipate that our NAP- $\mathrm{CF}_{3}$ could not only go deeper to investigate lipid droplets associated changes with high signal-to-noise ratio, but also potentially offer a simple, fast and reliable way to diagnose lipid droplets related disease like fatty liver diseases in live samples. Therefore, such excellent two-photon tissue imaging ability of NAP$\mathrm{CF}_{3}$ renders it as a tremendous tool to visualize lipid droplets-associated biomedical application in live tissues.
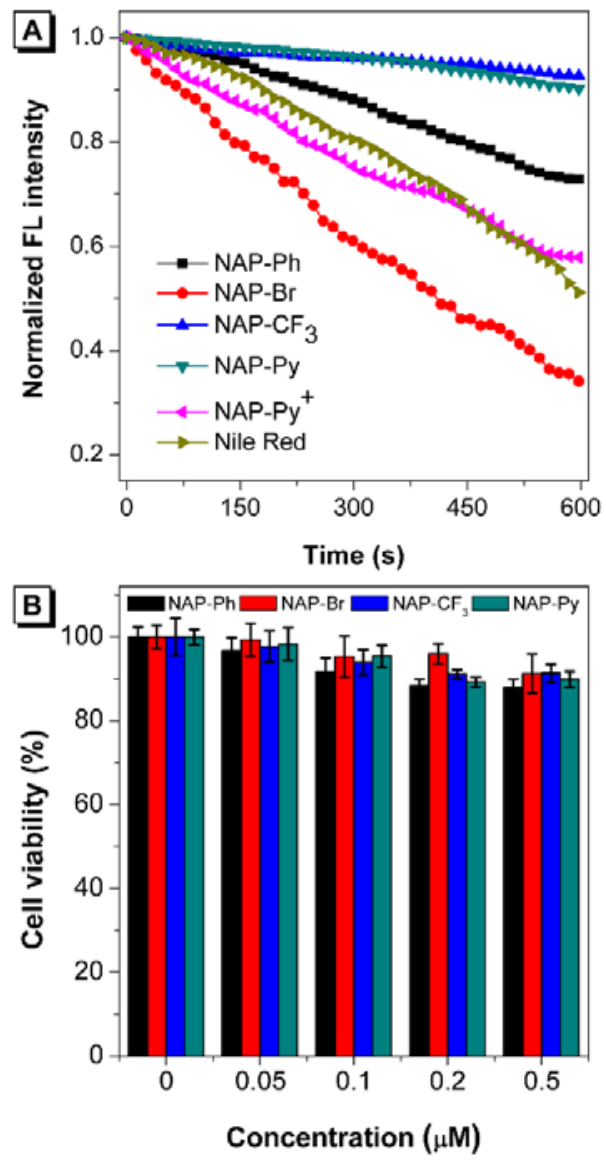

Figure 7. (A) Photostability of NAP AIEgens and Nile Red in HeLa cells under continuous irradiation. Irradiation conditions: for NAP AIEgens: $405 \mathrm{~nm}$ laser, laser power $=12 \%$; for Nile Red: $543 \mathrm{~nm}$ laser, laser power $=12 \%$. (B) Cytotoxicity of NAP AIEgens in HeLa cells.

Photostability and cytotoxicity. The NAP-AIEgens already demonstrate excellent bioimaging characteristics, how about their photostability and cytotoxicity? To check the photostability of NAP AIEgens, we continuous irradiated their stained cells with confocal lasers and collected the fluorescence signal at every second. After continuous irradiation for $10 \mathrm{~min}$, more than $90 \%$ of the initial fluorescence intensity still remained in NAP- $\mathrm{CF}_{3}$ and NAP-Py, while the remaining molecules suffered different extent of emission drop (Figure $7 \mathrm{~A}$ ). However, such situation was much better than that of Nile Red under the same condi- 
tion. These data indicate that NAP- $\mathrm{CF}_{3}$ and NAP-Py can be used for long-term monitoring of the dynamic changes of lipid droplets in biological samples. Furthermore, standard MTT (3-(4,5-dimethylthiazol-2-yl)-2,5-diphenyl$2 \mathrm{H}$-tetrazolium) assays were performed to evaluate the cytotoxicity of NAP AIEgens in live cells. As seen in Figure ${ }_{7} \mathrm{~B}$ and $\mathrm{S}_{42}$, after incubation in HeLa cells for $24 \mathrm{~h}$, the viability of HeLa was still high, revealing that these AIEgens exhibit negligible cytotoxicity within the tested concentrations and are biocompatible with the biological samples.

\section{CONCLUSIONS}

In this work, new AIEgens (NAP-Ph, NAP-Br, NAP-CF and NAP-Py) for specific two-photon lipid droplets staining in live cells and live tissues were designed and synthesized. Their photophysical properties were investigated by one- and two-photon fluorescence spectroscopy, DFT calculation and single-crystal X-ray diffraction. The new AIEgens exhibit large Stokes shift (>110 nm), high solidstate fluorescence quantum yield (up to $30 \%$ ) and good two-photon absorption cross-section (45-100 GM at 860 $\mathrm{nm})$. Live cell imaging experiments demonstrated that they showed specific lipid droplets staining with high signal-to-noise ratio at ultra-low concentration (50 $\mathrm{nM}$ ). Such concentration was the lowest concentration for lipid droplets visualization in live cells reported so far. In addition, the $C \log \mathrm{P}$ values revealed that these lipophilic AIEgens could specifically locate in lipid droplets. Using $\mathrm{NAP}-\mathrm{CF}_{3}$ as an example, two-photon specific imaging of lipid droplets in live mice liver tissues and visualization of lipid droplets with a high signal-to-noise ratio at depth of up to about $70 \mu \mathrm{m}$ could be realized. The new AIEgens also exhibited high biocompatibility and good photostability. This work provides a direct way to rationally develop new AIEgens for selective lipid droplets visualization and suggests that NAP AIEgens can be used as powerful tools to unravel the roles of lipid droplets play in cellular physiology and in diseases.

\section{ASSOCIATED CONTENT}

Supporting Information.

The Supporting Information is available free of charge on the ACS Publications website at DOI: 10.1021/acs.chemmater.8bo1943.

Materials and Methods; ${ }^{1} \mathrm{H}$ NMR, ${ }^{13} \mathrm{C}$ NMR, ${ }^{19} \mathrm{~F}$ NMR and HRMS spectra of new compounds; Crystallographic data; Photophysical data and Imaging data (PDF)

All optimized CIF structures (CCDC 1584797-158480o) (CIF)

Two-photon (TP) live tissue imaging along the $Z$-axis (Movie $\mathrm{S} 1)$

\section{AUTHOR INFORMATION}

\section{Corresponding Author}

*yuxq@sdu.edu.cn

*tangbenz@ust.hk

\section{ORCID}

Guangle Niu: 0ooo-0oo2-5403-6880
Jianguo Wang: 0ooo-0003-0984-9716

Xing Feng: oooo-ooo2-4273-979X

Ryan T. K. Kwok: oooo-ooo2-6866-3877

Mark R. J. Elsegood: oooo-0002-8984-4175

Xiaoqiang Yu: oooo-0oo2-4313-6464

Ben Zhong Tang: 0ooo-0oo2-0293-964X

\section{Author Contributions}

"These authors contributed equally.

Notes

The authors declare no competing financial interest.

\section{ACKNOWLEDGMENT}

This work was partially supported by the National Natural Science Foundation of China (21788102, 51773111, 21490570 and 21490574), the National Basic Research Program of China (973 Program: 2013CB834701 and 2013CB834702), the Research Grants Council of Hong Kong (16301614, 16305015, AHKUST 605/16, N_HKUST604/14 and AoE/P-02/12), and the Innovation and Technology Commission (ITC-CNERC14SCo1 and ITCPD/17-9) and the Science and Technology Plan of Shenzhen (JCYJ20170818113851132, JCYJ20170818113840164, JCYJ20160229205601482 and JCYJ20140425170011516).

\section{REFERENCES}

(1) Thiam, A. R.; Farese Jr, R. V.; Walther, T. C. The biophysics and cell biology of lipid droplets. Nat. Rev. Mol. Cell Biol. 2013, 14, 775-786.

(2) Walther, T. C.; Jr., R. V. F. Lipid Droplets and Cellular Lipid Metabolism. Annu. Rev. Biochem. 2012, 81, 687714 .

(3) Krahmer, N.; Farese, R. V.; Walther, T. C. Balancing the fat: lipid droplets and human disease. EMBO Mol. Med. 2013, 5, 973-983.

(4) DiDonato, D.; Brasaemle, D. L. Fixation Methods for the Study of Lipid Droplets by Immunofluorescence Microscopy. J. Histochem. Cytochem. 2003, 51, 773-780.

(5) Fujimoto, T.; Ohsaki, Y.; Suzuki, M.; Cheng, J. Imaging Lipid Droplets by Electron Microscopy. Methods Cell Bio. 2013, 116, 227-251.

(6) Zhang, C.; Li, J.; Lan, L.; Cheng, J.-X. Quantification of Lipid Metabolism in Living Cells through the Dynamics of Lipid Droplets Measured by Stimulated Raman Scattering Imaging. Anal. Chem. 2017, 89, 4502-4507.

(7) Haque, A.; Faizi, M. S. H.; Rather, J. A.; Khan, M. S. Next generation NIR fluorophores for tumor imaging and fluorescence-guided surgery: A review. Bioorg. Med. Chem. 2017, 25, 2017-2034.

(8) Chevalier, A.; Renard, P.-Y.; Romieu, A. Azo-Based Fluorogenic Probes for Biosensing and Bioimaging: Recent Advances and Upcoming Challenges. Chem. Asian J. 2017, 12, 2008-2028.

(9) Chen, Y.; Bai, Y.; Han, Z.; He, W.; Guo, Z. Photoluminescence imaging of $\mathrm{Zn} 2+$ in living systems. Chem. Soc. Rev. 2015, 44, 4517-4546.

(10) Pawlicki, M.; Collins, H. A.; Denning, R. G.; Anderson, H. L. Two-Photon Absorption and the Design of TwoPhoton Dyes. Angew. Chem. Int. Ed. 2009, 48, 32443266.

(11) Kim, H. M.; Cho, B. R. Small-Molecule Two-Photon Probes for Bioimaging Applications. Chem. Rev. 2015, 115, 5014-5055.

(12) Spandl, J.; White, D. J.; Peychl, J.; Thiele, C. Live Cell Multicolor Imaging of Lipid Droplets with a New Dye, LD540. Traffic 2009, 10, 1579-1584. 

dansylpentane as a Blue-Fluorescent Lipid-Droplet Marker for Multi-Color Live-Cell Imaging. PLOS ONE 2012, 7, e32693.

(14) Lee, J. H.; So, J.-H.; Jeon, J. H.; Choi, E. B.; Lee, Y.-R.; Chang, Y.-T.; Kim, C.-H.; Bae, M. A.; Ahn, J. H. Synthesis of a new fluorescent small molecule probe and its use for in vivo lipid imaging. Chem. Commun. 2011, 47, 7500-7502.

(15) Kim, E.; Lee, S.; Park, S. B. A Seoul-Fluor-based bioprobe for lipid droplets and its application in imagebased high throughput screening. Chem. Commun. 2012, 48, 2331-2333.

(16) Lee, Y.; Na, S.; Lee, S.; Jeon, N. L.; Park, S. B. Optimization of Seoul-Fluor-based lipid droplet bioprobes and their application in microalgae for bio-fuel study. Mol. Biosyst. 2013, 9, 952-956.

(17) Bader, C. A.; Brooks, R. D.; Ng, Y. S.; Sorvina, A.; Werrett, M. V.; Wright, P. J.; Anwer, A. G.; Brooks, D. A.; Stagni, S.; Muzzioli, S.; Silberstein, M.; Skelton, B. W.; Goldys, E. M.; Plush, S. E.; Shandala, T.; Massi, M. Modulation of the organelle specificity in Re(i) tetrazolato complexes leads to labeling of lipid droplets. RSC Adv. 2014, 4, 16345-16351.

(18) Öberg, E.; Appelqvist, H.; Nilsson, K. P. R. Non-fused Phospholes as Fluorescent Probes for Imaging of Lipid Droplets in Living Cells. Front. Chem. 2017, 5, 28.

(19) Appelqvist, H.; Stranius, K.; Börjesson, K.; Nilsson, K. P. R.; Dyrager, C. Specific Imaging of Intracellular Lipid Droplets Using a Benzothiadiazole Derivative with Solvatochromic Properties. Bioconjugate Chem. 2017, 28, 1363-1370.

(20) Sk, B.; Thakre, P.; Tomar, R. S.; Patra, A. A pyridoindole based multifunctional bioprobe: $\mathrm{pH}$-induced fluorescence switching and specific targeting of lipid droplets. Chem. Asian J. 2017, 12, 2501-2509.

(21) Tang, J.; Zhang, Y.; Yin, H.-Y.; Xu, G.; Zhang, J.-L. Precise Labeling and Tracking of Lipid Droplets in Adipocytes Using a Luminescent ZnSalen Complex. Chem. Asian J. 2017, 12, 2533-2538.

(22) Mei, J.; Hong, Y.; Lam, J. W. Y.; Qin, A.; Tang, Y.; Tang, B. Z. Aggregation-Induced Emission: The Whole Is More Brilliant than the Parts. Adv. Mater. 2014, 26, 5429-5479.

(23) Goel, A.; Sharma, A.; Kathuria, M.; Bhattacharjee, A.; Verma, A.; Mishra, P. R.; Nazir, A.; Mitra, K. New Fluoranthene FLUN-550 as a Fluorescent Probe for Selective Staining and Quantification of Intracellular Lipid Droplets. Org. Lett. 2014, 16, 756-759.

(24) Sharma, A.; Umar, S.; Kar, P.; Singh, K.; Sachdev, M.; Goel, A. A new type of biocompatible fluorescent probe AFN for fixed and live cell imaging of intracellular lipid droplets. Analyst 2016, 141, 137-143.

(25) Wu, A.; Kolanowski, J. L.; Boumelhem, B. B.; Yang, K.; Lee, R.; Kaur, A.; Fraser, S. T.; New, E. J.; Rendina, L. M. A Carborane-Containing Fluorophore as a Stain of Cellular Lipid Droplets. Chem. Asian J. 2017, 12, 17041708.

(26) Luo, J.; Xie, Z.; Lam, J. W. Y.; Cheng, L.; Chen, H.; Qiu, C.; Kwok, H. S.; Zhan, X.; Liu, Y.; Zhu, D.; Tang, B. Z. Aggregation-induced emission of 1-methyl-1,2,3,4,5pentaphenylsilole. Chem. Commun. 2001, 1740-1741.

(27) Gabr, M. T.; Christopher Pigge, F. A turn-on AIE active fluorescent sensor for $\mathrm{Hg}_{2}+$ by combination of 1,1bis(2-pyridyl)ethylene and thiophene/bithiophene fragments. Mater. Chem. Front. 2017, 1, 1654-1661.
Chen, Y.; Zhang, W.; Cai, Y.; Kwok, R. T. K.; Hu, Y.; Lam, J. W. Y.; Gu, X.; He, Z.; Zhao, Z.; Zheng, X.; Chen, B.; Gui, C.; Tang, B. Z. AIEgens for dark through-bond energy transfer: design, synthesis, theoretical study and application in ratiometric $\mathrm{Hg}_{2}+$ sensing. Chem. Sci. 2017, 8, 2047-2055.

(29) Zhang, J.; Zheng, M.; Zhang, F.; Xu, B.; Tian, W.; Xie, Z. Supramolecular Hybrids of AIEgen with Carbon Dots for Noninvasive Long-Term Bioimaging. Chem. Mater. 2016, 28, 8825-8833.

(30) Yuan, Y.; Liu, B. Visualization of Drug Delivery Processes with AIEgens. Chem. Sci. 2017, 8, 2537-2546.

(31) Zhao, J.; Feng, Z.; Zhong, D.; Yang, X.; Wu, Y.; Zhou, G.; Wu, Z. Cyclometalated Platinum Complexes with Aggregation-Induced Phosphorescence Emission Behavior and Highly Efficient Electroluminescent Ability. Chem. Mater. 2018, 30, 929-946.

(32) An, B.-K.; Kwon, S.-K.; Jung, S.-D.; Park, S. Y. Enhanced Emission and Its Switching in Fluorescent Organic Nanoparticles. J. Am. Chem. Soc. 2002, 124, 1441014415 .

(33) Qian, H.; Cousins, M. E.; Horak, E. H.; Wakefield, A.; Liptak, M. D.; Aprahamian, I. Suppression of Kasha's rule as a mechanism for fluorescent molecular rotors and aggregation-induced emission. Nat. Chem. 2017, 9, $83-87$.

(34) Mei, J.; Leung, N. L. C.; Kwok, R. T. K.; Lam, J. W. Y.; Tang, B. Z. Aggregation-Induced Emission: Together We Shine, United We Soar! Chem. Rev. 2015, 115, 1171811940 .

(35) Qian, J.; Tang, B. Z. AIE Luminogens for Bioimaging and Theranostics: from Organelles to Animals. Chem 2017, 3, 56-91.

(36) Wang, E.; Zhao, E.; Hong, Y.; Lam, J. W. Y.; Tang, B. Z. A highly selective AIE fluorogen for lipid droplet imaging in live cells and green algae. J. Mater. Chem. B 2014, 2, 2013-2019.

(37) Kang, M.; Gu, X.; Kwok, R. T. K.; Leung, C. W. T.; Lam, J. W. Y.; Li, F.; Tang, B. Z. A near-infrared AIEgen for specific imaging of lipid droplets. Chem. Commun. 2016, 52, 5957-5960.

(38) Wang, Z.; Gui, C.; Zhao, E.; Wang, J.; Li, X.; Qin, A.; Zhao, Z.; Yu, Z.; Tang, B. Z. Specific Fluorescence Probes for Lipid Droplets Based on Simple AIEgens. ACS Appl. Mater. Interfaces 2016, 8, 10193-10200.

(39) Gao, M.; Su, H.; Lin, Y.; Ling, X.; Li, S.; Qin, A.; Tang, B. Z. Photoactivatable aggregation-induced emission probes for lipid droplets-specific live cell imaging. Chem. Sci. 2017, 8, 1763-1768.

(40) Gao, M.; Su, H.; Li, S.; Lin, Y.; Ling, X.; Qin, A.; Tang, B. Z. An easily accessible aggregation-induced emission probe for lipid droplet-specific imaging and movement tracking. Chem. Commun. 2017, 53, 921-924.

(41) Jiang, M.; Gu, X.; Lam, J. W. Y.; Zhang, Y.; Kwok, R. T. K.; Wong, K. S.; Tang, B. Z. Two-photon AIE bio-probe with large Stokes shift for specific imaging of lipid droplets. Chem. Sci. 2017, 8, 5440-5446.

(42) Wang, D.; Su, H.; Kwok, R. T. K.; Shan, G.; Leung, A. C. S.; Lee, M. M. S.; Sung, H. H. Y.; Williams, I. D.; Lam, J. W. Y.; Tang, B. Z. Facile Synthesis of Red/NIR AIE Luminogens with Simple Structures, Bright Emissions, and High Photostabilities, and Their Applications for Specific Imaging of Lipid Droplets and Image-Guided Photodynamic Therapy. Adv. Funct. Mater. 2017, 27, 1704039.

(43) Horobin, R. W.; Rashid-Doubell, F.; Pediani, J. D.; Milligan, G. Predicting small molecule fluorescent probe 
localization in living cells using QSAR modeling. 1. Overview and models for probes of structure, properties and function in single cells. Biotech. Histochem. 2013, 88, 440-46o.

(44) Yuan, L.; Wang, L.; Agrawalla, B. K.; Park, S.-J.; Zhu, H.; Sivaraman, B.; Peng, J.; Xu, Q.-H.; Chang, Y.-T. Development of Targetable Two-Photon Fluorescent Probes to Image Hypochlorous Acid in Mitochondria and Lysosome in Live Cell and Inflamed Mouse Model. J. Am. Chem. Soc. 2015, 137, 5930-5938.

(45) Niu, G.; Liu, W.; Xiao, H.; Zhang, H.; Chen, J.; Dai, Q.; Ge, J.; Wu, J.; Wang, P. Keto-benzo[h]-CoumarinBased Near-Infrared Dyes with Large Stokes Shifts for Bioimaging Applications. Chem. Asian J. 2016, 11, 498504 .

(46) Würthner, F.; Thalacker, C.; Diele, S.; Tschierske, C. Fluorescent J-type Aggregates and Thermotropic Columnar Mesophases of Perylene Bisimide Dyes. Chem. Eur. J. 2001, 7, 2245-2253.

(47) Choi, S.; Bouffard, J.; Kim, Y. Aggregation-induced emission enhancement of a meso-trifluoromethyl BODIPY via J-aggregation. Chem. Sci. 2014, 5, 751-755.

(48) Niu, G.; Liu, W.; Zhou, B.; Xiao, H.; Zhang, H.; Wu, J.; Ge, J.; Wang, P. Deep-Red and Near-Infrared Xanthene Dyes for Rapid Live Cell Imaging. J. Org. Chem. 2016, 81, 7393-7399.

(49) Frisch, M. J.; Trucks, G. W.; Schlegel, H. B.; Scuseria, G. E.; Robb, M. A.; Cheeseman, J. R.; Montgomery, J. A., Jr.; Vreven, T.; Kudin, K.; Burant, J. C. et al., Gaussian o9, revision A.02; Gaussian, Inc.: Wallingford, CT, 2009.
(50) Makarov, N. S.; Drobizhev, M.; Rebane, A. Two-photon absorption standards in the 550-1600 nm excitation wavelength range. Opt. Express 2008, 16, 4029-4047.

(51) Zhang, R.; Sun, Y.; Tian, M.; Zhang, G.; Feng, R.; Li, X.; Guo, L.; Yu, X.; Sun, J. Z.; He, X. A phospholipidbiomimetic fluorescent mitochondrial probe with ultrahigh selectivity enables in-situ and high-fidelity tissue imaging. Anal. Chem. 2017, 89, 6575-6582.

(52) Ishikawa, M.; Hashimoto, Y. Improvement in Aqueous Solubility in Small Molecule Drug Discovery Programs by Disruption of Molecular Planarity and Symmetry. J. Med. Chem. 2011, 54, 1539-1554.

(53) Su, D.; Teoh, C. L.; Wang, L.; Liu, X.; Chang, Y.-T. Motion-induced change in emission (MICE) for developing fluorescent probes. Chem. Soc. Rev. 2017, 46, 48334844 .

(54) Liu, Q.; Guo, B.; Rao, Z.; Zhang, B.; Gong, J. R. Strong Two-Photon-Induced Fluorescence from Photostable, Biocompatible Nitrogen-Doped Graphene Quantum Dots for Cellular and Deep-Tissue Imaging. Nano Lett. 2013, 13, 2436-2441.

(55) Onal, G.; Kutlu, O.; Gozuacik, D.; Dokmeci Emre, S. Lipid Droplets in Health and Disease. Lipids Health Dis. 2017, 16, 128.

(56) Li, M.; Xu, C.; Shi, J.; Ding, J.; Wan, X.; Chen, D.; Gao, J.; Li, C.; Zhang, J.; Lin, Y.; Tu, Z.; Kong, X.; Li, Y.; Yu, C. Fatty acids promote fatty liver disease via the dysregulation of 3-mercaptopyruvate sulfurtransferase/hydrogen sulfide pathway. Gut 2018, DOI: 10.1136/gutjnl-2017-313778.

\section{Table of Contents}

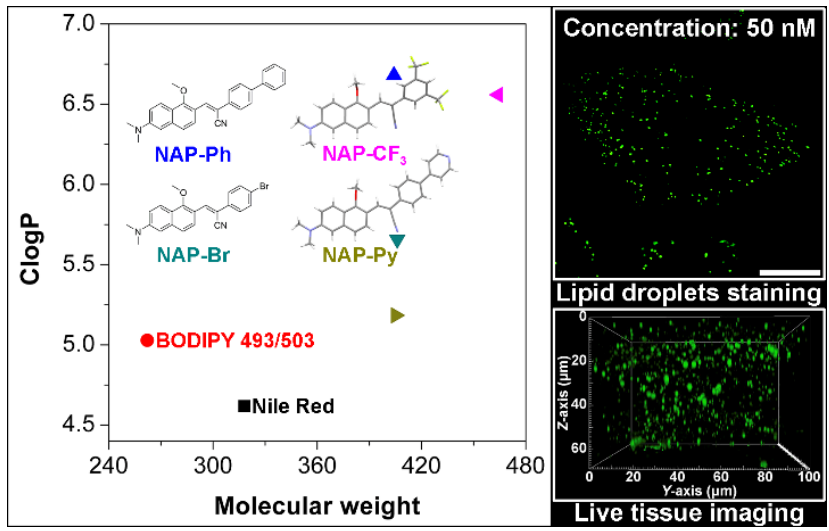

$\left(60{ }^{*} 600 \mathrm{dpi}\right)$ 